\title{
O QUE HÁ DE "CAMPO" NAS POLÍTICAS EDUCACIONAIS PARA O CAMPO?
}

\section{WHAT'S FROM "FIELD" IN THE FIELD, WHEN WE TALK ABOUT EDUCATIONAL POLICIES FOR THE COUNTRYSIDE?}

\author{
Melquisedeque de Oliveira Fernandes ${ }^{1}$ \\ UFERSA: https://orcid.org/0000-0002-7030-2640
}

DOI: 10.21680/1982-1662.2021v4n31ID26434

\section{Resumo}

Visto a partir do urbano, o campo é um lugar onde prevalecem modalidades de cooperação baseadas no princípio camponês de reciprocidade. Esse tenderia a deteriorar-se diante do avanço das relações inspiradas no utilitarismo e pragmatismo típico do projeto burguês de sociedade. O tipo de cooperação sociotécnica atribuída ao campesinato - em oposição ao processo de urbanização - é o da ajuda mútua e troca de favores, das quais deduzimos a noção de “reciprocidades”. Para além de sustentar uma forma sócio-histórica de organização coletiva para produção, as reciprocidades também respondem pela produção subjetiva e simbólica de "sujeitos recíprocos". Nesse texto discutimos o papel educacional da educação do campo no que se refere a promover as práticas de reciprocidades e a produção de sujeitos recíprocos no contexto de duas políticas educacionais para o campo: o curso de Licenciatura Interdisciplinar em Educação do Campo da Universidade Federal Rural do Semiárido (Ledoc/Ufersa) e o curso de Ciências Sociais “da Terra" (Pronera/MST/UFRN).

Palavras-chave: Políticas educacionais. Educação do campo. Campesinato. Reciprocidades.

\footnotetext{
${ }^{1}$ E-mail: melquisedeque.fernandes@ufersa.edu.br
} 


\begin{abstract}
Seen from the urban point of view, the countryside is a place where cooperation's forms based on the peasant's principle of reciprocity prevail. This would tend to deteriorate in the face of the advance of relations inspired by the utilitarianism and typical pragmatism of the bourgeois project of society. The type of socio-technical cooperation attributed to the peasantry - as opposed to the urbanization process - is that of mutual aid and exchange of favors, from which we deduce the notion of "reciprocity". In addition to sustaining a socio-historical form of collective organization for production, reciprocity also account for the subjective and symbolic production of "reciprocal person". In this text we discuss the educational role of rural education in terms of promoting reciprocity practices and the production of reciprocal person in the context of two educational policies for the countryside: the Interdisciplinary Licentiate Course in Rural Education at the Universidade Federal Rural do Semiárido (Ledoc/Ufersa) and the Social Sciences course "of the land" (Pronera/MST/UFRN).
\end{abstract}

Keywords: Educational policies. Countryside education. Peasantry. Reciprocity.

\title{
O que chamamos de "campo"
}

De modo genérico a noção de campo se refere a uma forma específica de ocupação e uso do espaço que é ao mesmo tempo anterior e contemporânea ao modo de produção capitalista, cuja delimitação de seu significado atual foi se estruturando mediante uma relação de oposição, e ao mesmo tempo controle administrativo por parte da cidade. Ou seja, cidade e campo são um duplo que Henri Lefebvre caracterizou em sua teoria como um processo de diferenciação cada vez mais interdependente em que a cidade estende ao campo certa "organização do trabalho da terra em determinadas condicionantes técnicas (ferramentas) e sociais (divisão do trabalho e modalidades de cooperação, por exemplo)" (Potratz, 2018, 563). Visto a partir do urbano, o campo é um lugar onde prevalecem “modalidades de cooperação", baseadas no princípio camponês de reciprocidade, que tendem a se tornarem obsoletas diante do avanço das relações contratuais de trabalho, de compra e venda de mão de obra e do excedente produzido. 
Sob a perspectiva do evolucionismo vulgar, o campo também pode visto como um intermediário, um estágio - no que se refere a certo uso ordenado do território entre o que se chama de primitivo e civilizado. Esse tipo de perspectiva tende a privilegiar os aspectos de racionalidade planificada das cidades como uma espécie de devir histórico para os povos autóctones que, por não estarem orientados para acumulação material, desenvolvem uma relação de exploração mais equilibrada com seu habitat. Do ponto de vista das relações sociais o campo seria algum tipo de “primitivo avançado" onde já se pode verificar o imperativo da produção organizada para o excedente e o predomínio de assimetrias sociais próximas do padrão burguês de sociedade, como os estamentos que parecem com as classes. Desse modo, tomando a modernidade capitalista em seu sentido teleológico, o campo é um passado ainda presente, e o primitivo um passado presumidamente superado.

Sociologicamente a ideia de campo só pode ser compreendida quando observado seu correspondente modo de vida, isto é, o campesinato. Antes de tudo a ideia de campesinato opera como uma espécie de noção guarda-chuva que abriga uma imensa heterogeneidade de formas de ocupar e viver da terra, cuja organização é historicamente determinada em bases comunitárias, onde parte dos bens e recursos é socializado e sua exploração responde à uma disciplina de trabalho comunitário (LEFEBVRE, 1978).

Enquanto etapa superada, enquanto estágio anterior na composição das atuais relações de produção de tipo capitalista, o campo é visto não somente como lugar do atraso, mas como espaço de interações em que certo modo pré-capitalista de "ser e estar no mundo" persiste apesar de forças contrárias. 0 tipo de cooperação sociotécnica atribuída ao campesinato - em oposição ao processo de urbanização - é o da ajuda mútua e troca de favores, que se vulgarizou inclusive no meio acadêmico mediante uma visão romântica do camponês como sujeitos não contaminados pelo utilitarismo característico das relações de mercado. Essa visão se baseia em um fato atestado na literatura sobre o tema de que o camponês tende a manter (defender) seu modo de vida específico diante da ameaça que o urbano lhes representa: "lutar contra mudanças e inovações tidas como ameaças potenciais à ordem interna, que se esforçam por manter" (WOLF, 1976, p. 119).

Diante disso podemos deduzir que o que é característico da organização social do campo é uma espécie de persistência histórica de certos atributos de suas relações, 
que na ausência de algum deles dissolve-se também seu modo de vida específico. Não faz sentido, portanto, falar de camponês em contextos em que estão ausentes as noções família como unidade de produção autônoma, mas interligadas pela necessidade de exploração de bens comuns, mediante formas historicamente sedimentadas de trabalho de base comunitária, e, principalmente, as reciprocidades que os ligam uns aos outros.

Partimos do pressuposto que as reciprocidades camponesas compreendem um poderoso fundamento moral que viabiliza as trocas materiais e simbólicas entre os sujeitos, e que thes oferece como resultado o próprio adensamento coletivo dos laços de ajuda mútua, conferindo-lhes certo grau de unidade e coesão. Ao mesmo tempo forma sujeitos que agem de acordo com os princípios de reciprocidade e assim esperam uns dos outros, ou seja, a prática das reciprocidades, dentro de certo ambiente de relações, cria os próprios sujeitos como seres recíprocos.

Essas reciprocidades foram originalmente observadas por Durkheim que sumariamente as definiu como formas de solidariedade mecânica, típicas de sociedades pré-industriais. Na sequência, Marcel Mauss estudou as reciprocidades no contexto de sua teoria da dádiva, na qual "dar, receber e devolver" é um movimento constante que tente para o adensamento dos laços entre sujeitos cada vez mais implicados em relações de dependência mútua: tanto no que se refere ao contexto da produção material, no qual se praticam as trocas de favores, quanto na produção da ordem simbólica, em um cotidiano marcado por relações que excedem a troca simples, posto que são investidas também de afetos e subjetividades. De modo muito sintético podemos dizer que as reciprocidades são relações de troca extrapoladas pelos sentimentos nelas contidos, dentre os quais destaca-se a confiança.

Para Mauss a devolução da dádiva é explicada pela força espiritual presente na coisa que foi dada: "a reciprocidade supõe uma preocupação pelo outro. Não se pode estar inquieto do outro sem se preocupar com suas condições de existência. Tal preocupação torna-se, portanto, hospitalidade, dádiva de alimentos e víveres, proteção, ou seja, motivos ou obrigações para produzir" (SABOURIN, 2008. P. 135). A "economia primitiva" se desenvolveu mediante um cultivo da disposição dos sujeitos em dar e receber. Mas "se para ser é preciso dar, para dar, é necessário produzir". É nesse sentido que os sujeitos se produzem, uns aos outros, material e subjetivamente, como seres recíprocos. 
Isso quer dizer que o objetivo ético e político não é apenas assegurar as condições materiais de vida decentes para todos os seres humanos para elas em si -, nem de garantir por si só a liberdade dos indivíduos psíquicos e coletivos, mas de assegurar a maximização da sua individualização no sentido de exprimir a sua singularidade, como garantia do seu pertencimento diferenciado a coletivos ou à totalidade humana (SABOURIN, 2008. p. 136).

No que se refere as políticas educacionais para a educação do campo, partimos do pressuposto de que, apesar da importância que tem as reciprocidades como elemento estratégico para reprodução das relações que caracterizam “o campo", elas ocupam um lugar reduzido na construção ou no desing dessas políticas. Nosso objetivo com esse texto é problematizar a presença e os efeitos das reciprocidades camponesas nas políticas educacionais para o campo, tendo em vista o investimento que existe em torno de especificidades - ou singularidades - educacionais como forma de manutenção desses grupos, a fim de evitar que sejam completamente integrados a lógica globalizante do mercado e/ou Estado.

A continuidade de certas características sem as quais não se pode falar em “campo” passa necessariamente pela educação enquanto projeto no qual as práticas de reciprocidade são estimuladas e ritualmente praticadas dentro das diferentes ações educativas, no interior e fora da escola do campo. Estamos falando, portanto, da educação do campo como um espaço em que é discutido e disputado o sentido da vida no campo - e, ao mesmo tempo, voltado para a sociedade em geral - em que estão fixados valores como a ajuda mútua, o fazer coletivo, ou mesmo o uso sustentável do território, ou seja, o que Van Der Ploeg (2009) chama de “capital ecológico" como alternativa ao capital meramente econômico.

Contudo, existe uma contradição aparente em esperar que as reciprocidades camponesas possam ser ritualizadas nos diferentes ambientes escolares de educação do campo, uma vez que o próprio avanço da escolarização, na forma do que Durkheim denominou de "fato educacional", carrega consigo o que mais adiante Weber chamaria de "secularização". Isso que por sua vez tem a ver com um processo mais ou menos inexorável de deslocamento dos antigos padrões de autoridade e legitimidade tradicionais para o campo da racionalidade prática e instrumental; cujo resultado se verifica na perda gradual de elementos místicos, imensuráveis e subjetivos, enquanto elos significativos entre os sujeitos, para cederem lugar a valores pretensamente universais, livres de ambiguação e emocionalmente “frios". 
A teoria da secularização é uma teoria geral da mudança societal e consiste de um corpo empírico coerente de generalizações empíricas que repousa sobre premissas weberianas fundamentais. De acordo com essas premissas familiares, em certas sociedades as visões de mundo e as instituições ancoradas na transcendência perdem influência social e cultural como resultado da dinâmica da racionalização. [...] Porque as sociedades ocidentais foram as mais afetadas por processos de racionalização, elas se tornaram profundamente secularizadas. (Lechner apud Pierucci, 1998, p. 53).

Sendo a escola ao mesmo tempo produto e cúmplice em relação ao avanço do processo de secularização na sociedade, ela procedimentaliza a racionaliza a transmissão inter-gacional de certo tipo de conhecimento considerado socialmente útil e importante, grosso modo, o que Bourdieu (1998) chama de capital cultural.

Apesar de representar um projeto de planificação e controle cultural - de caráter urbanocêntrico e reprodutora da ordem social burguesa mediante o monopólio do conhecimento socialmente legítimo - o fato educacional enquanto processo pode ser preenchido de outros sentidos. Mediante sua forma singular, a educação do campo representa um autêntico desdobramento das lutas populares contra a ordem estabelecida, sugerindo uma ocupação da escola a fim de convertê-la em meio de reprodução simbólica da ordem camponesa, que por sua vez apresenta-se como uma das alternativas ao capitalismo.

Em alguns momentos, como por exemplo, nas místicas ou no teatro do oprimido, ambos muito praticados nas ações de educação do campo, essa ambivalência entre transcendência e racionalidade se compatibilizam na medida em que estudantes encarnam no próprio corpo dramas comuns, de um passado que julgam necessário rememorar e de destacar valores referentes a um sentido de vida compartilhado. Uma noção em particular nos ajuda a compreender como racionalidade e subjetividade podem ser compatibilizadas nas ações educativas, mediante o que o filósofo Antonin Artaud chama de "autoconsciência dramática":

Uma revolta não desconectada da realidade política e propiciadora de um novo encantamento da subjetividade dos indivíduos e da própria palavra. Um reencantamento que tenta retirar o indivíduo da zona do homo patiens e trazê-lo em movimento à superfície de uma cultura de menos melancolia, angústia, depressão, dissimulação [...]. Para tentar estabelecer os parâmetros dessa revolta caótica e organizadora da cultura, será necessária uma revolta ética da religião entre pensamento, política, poesia, como um diálogo íntimo que forneça novas lufadas de utopia aos sujeitos [grifos nossos] (GALENO, 2005, p. 
100).

Esse potencial de reencantamento do mundo que a educação do campo carrega consigo depende basicamente de sua capacidade de sustentar os caracteres tipicamente atribuídos aos camponeses. As reciprocidades estão no centro de uma economia simbólica em que o valor subjetivo das trocas opera decisivamente na reprodução dos diferentes segmentos camponeses, assim como as trocas de mercado operam decisivamente na conformação de uma forma de ser e estar no mundo compatível com o modo de produção capitalista. As práticas camponesas de ajuda mútua foram percebidas não somente dentro da tradição weberiana como também dentro da tradição marxista enquanto algo diferente e em vias de deterioração, na medida do avanço da economia de mercado.

Nas palavras de Abramovay (2007, p. 33): “Sob o ângulo marxista o camponês só pode ser definido pela tragédia de seu destino social: ele será fatalmente extinto pela própria dinâmica da diferenciação entre os produtores, bem como será incapaz de resistir à concorrência das grandes empresas agrícolas". A fim e a cabo, na obra de Marx o campesinato caminha rumo a algum tipo de fatalidade que se refere a deixar de ser camponês pela impossibilidade de reprodução social de suas bases materiais de cooperação comunitária - o acesso coletivo à terra - dando lugar a forma capitalista de cooperação no marco de relações assalariadas.

Em sentido equivalente, Weber também presume algum destino trágico para o modo de vida camponês na medida em que compreende o processo de secularização como uma sobreposição de sentido de vida entre os indivíduos que passam cada vez mais a compartilhar a razão instrumental como elo significativo entre eles. Isso equivale dizer, em outras palavras, que a secularização para este autor representa um projeto de dominação europeu que se estende pelo mundo, levado a cabo por uma crença incutida nos sujeitos sobre a importância e caráter universal do pensamento utilitarista, que reflete justamente a forma dos europeus se relacionam como o restante do mundo desde o início do colonialismo.

"Secularização", então, passa por acentuada extensão semântica e torna-se uma categoria histórico-filosófica portadora da pretensão de interpretar todo o curso da história universal como gênese da nossa ocidental modernidade sociopolítica e tecno-científica. Nesta nova e expandida acepção, a secularização tem relação íntima com o processo 
da história do espírito e da sociedade que também por essa época passa a ser pensado como emancipação da sociedade burguesa (PIERUCCI, 1998, p. 64).

A escola, que é também um espaço de confinamento (FOUCALT, 1984), retira o camponês do contexto de suas relações de reciprocidade para incutir-lhes relações secularizadas. É desse modo que a escola responde pelo próprio processo de secularização no campo, convertendo modos ancestrais de viver em formas e de sentir e raciocinar tipicamente capitalistas. Uma vez que são incluídos no fato educacional, que traz consigo a noção de escola urbanocêntrica, os camponeses são encorajados pelos movimentos sociais do campo a encontrarem, na própria escola, uma possibilidade de afirmação de seus valores específicos.

Originalmente praticadas dentro das ações educativas dos movimentos sociais do campo - com destaque para o MST - as reciprocidades são frequentemente adaptadas em formas pedagógicas de ensinar e aprender a “dar, receber e devolver”. A mística é uma dessas formas, densa de significados, a partir da qual se recria os contornos de certa moral, de certos comportamentos ou forma de se relacionar em coletivo.

A mística é, em suma, um ritual político que, a um só tempo, oferece resistência às práticas do outro e reafirma a própria identificação, resultando daí uma superidentificação. Por seu viés, jovens e recémchegados à luta são interpelados. É dessa prática político-ritualística que os sem-terra tiram sua força e reafirmam suas convicções e seu pertencimento ao movimento. Uma prática através da qual afirmam e reafirmam sua identificação aos saberes do Movimento, reforçando sua luta e atualizando a memória social do Movimento. E, assim, vão tecendo sua trilha em direção à utopia [...] (FREDA, 2014).

Nas sessões que seguem, iremos analisar primeiro como contextos camponeses têm sido cada vez mais alvo de um reordenamento de suas relações sob o imperativo da racionalidade técnica e instrumental que privilegia elementos de planejamento, gestão da terra e controle administrativo. Em seguida, colocaremos em perspectiva as possibilidades de apropriação e ressignificação desses imperativos sob uma forma atualizada de ser camponês. Faremos isso tomando como base a análise de duas realidades educacionais: o curso de Licenciatura Interdisciplinar em Educação do Campo da Universidade Federal Rural do Semiárido (Ledoc/Ufersa) e o curso de Ciências Sociais “da Terra” (Pronera/MST/UFRN). 


\section{As reciprocidades e o processo de secularização}

Uma vez institucionalizada como formato obrigatório da transmissão intergeracional dos saberes camponeses a escola do campo passa a ser disputada, especialmente pelos movimentos sociais do campo, entre seu caráter conservador/urbanocêntrico e suas possibilidades emancipatórias. Essas possibilidades dependem de certa apropriação que fazem os movimentos sociais do campo das políticas públicas dirigidas para o setor, engajando-se na sua operacionalização de modo a interferir nas múltiplas coerções com vistas a produzir "efeitos de poder":

[...] isto é, os tipos de discurso que ela acolhe e faz funcionar como verdadeiros; os mecanismos e as instancias que permitem distinguir os enunciados verdadeiros dos falsos, a maneira como se sanciona uns e outros; as técnicas e os procedimentos que são valorizados para a obtenção da verdade; o estatuto daqueles que têm o encargo de dizer o que funciona como verdadeiro. (FOUCAULT, 2004, p. 12).

É nesse sentido que as políticas públicas, em especial as educacionais, criam novos campos de disputa entre os sentidos possíveis para a vida no campo, que ora pendem para a retórica do desenvolvimento, ora pendem para a afirmação de um modo de vida específico.

Nas comunidades rurais do Sertão Nordestino, paralelamente às
relações de câmbio mercantil, encontram-se prestações econômicas
não mercantis que correspondem à permanência de práticas de
reciprocidade camponesa, ancestrais ou readaptadas num contexto
novo. [...] a ineficiência e as dificuldades das políticas públicas
aplicadas nessas comunidades que, ignorando a coerência da lógica da
reciprocidade, persistem em propor apenas o desenvolvimento do
intercâmbio mercantil, baseado na acumulação material e na
concorrência para o lucro. (SABOURIN, 1999, p. 41)

Desde a criação do Pronaf em 1995, que segundo alguns especialistas foi o grande marco das políticas públicas para agricultura familiar (GRISA e SCHNEIDER, 2014), o incremento no volume de recursos públicos destinados a esses setores veio acompanhado pelo incentivo a modelos pré-concebidos de participação enquanto canal legítimo de interlocução entre setores camponeses organizados e Estado. Para tanto as associações são incentivadas, primeiro, com dispositivo de gestão coletiva da terra, mediante as quais os assentados fazem-se representar formalmente perante 0 governo, viabilizando a aquisição de créditos, maquinário e acesso a outras formas de 
investimento; segundo, as oportunizam enquanto espaços de encontro e diálogo entre atores sociais e camponeses, como prerrogativa de formação política de sujeitos já investidos em processos históricos de luta; terceiro, por serem legítimos, representam um espaços onde se exercitam certas práticas de reciprocidades, ainda que altamente afetadas pela racionalidade instrumental que lhe é característica.

Tal qual as escolas, as associações, cooperativas e outros espaços incentivados pelo Estado, que tem como "efeito de poder" a ampliação de seu alcance burocrático até os povos do campo, podem também se tornar uma base de luta do movimento camponês. A ocupação e o sentido dessas agremiações dependem da disputa em torno de qual papel desempenham dentro de cada comunidade. Sobre isso, as associações e cooperativas de produtores rurais são cercadas de uma nuance empresarial, com a perspectiva da concorrência e do lucro em primeiro plano, como afirmou Eric Sabourin “ignorando a coerência da lógica da reciprocidade".

Esse processo de flagrante racionalização das formas de cooperação camponesa desloca o peso das reciprocidades, que pelo seu caráter de ajuda mútua está diluído nas várias formas de interação cotidiana, para situá-los no campo específico da produção agrícola. Desde os anos 1950, quando o associativismo e cooperativismo se disseminaram pelo meio rural, mediante incentivo dos movimentos sociais do campo (GOHN, 2014), seja como forma de captação de recursos, seja como forma de organizar a luta camponesa, as formas de solidariedade anteriormente praticadas são recriadas dentro desses ambientes com relativo prejuízo do que estamos chamando aqui de reciprocidades e em proveito de códigos mais familiares e convenientes para o Estado e mercado.

Apesar da disputa em torno dessas diferentes extensões do Estado em direção as populações do campo - associações, cooperativas, escolas do campo, e suas correspondentes políticas públicas - tem pesado mais nesse processo a ideia de que o rural é uma parte quse fisiológica do urbano, com a finalidade última de lhe fornecer alimento. Basta ver, por exemplo, o bordão muito frequentemente utilizado para justificar as políticas públicas que afirmam que a agricultura familiar é responsável pelo abastecimento de $70 \%$ das mesas dos brasileiros. Além de falsa ${ }^{2}$, essa afirmação sintetiza uma forma de perceber o campo reduzido à sua dimensão produtiva, ao passo que lança para o plano do invisível ou do que Lefebvre (1999) chama de "campo Brasil?. Segurança Alimentar e Nutricional, v. 21, n. 1, p. 417-421, 2014. 
cego", a contribuição de seus sujeitos no que se refere a construção de relações de troca que não sejam meramente de compra e venda, mediadas pelo dinheiro como equivalente universal.

A questão aqui, entretanto, é sobre o lugar social que esses sujeitos ocupam dentro de um sistema de classificações e representações de mundo, cuja sua posição é definida em algum momento pretérito do processo civilizador (ELIAS, 1994) ou em relação ao próprio Estado e mercado enquanto agentes assediadores e potencialmente comprometedores de seu modo de vida. Mesmo quando oferece algum tipo de vantagem como, por exemplo, via políticas públicas, o Estado cumpre um papel de tipificar e categorizar a imensa e heterogênea composição do campesinato em formas diminutivas de trata-los como "produtores de baixa renda", "pequenos produtores" ou "agricultura de subsistência"; deduzindo-se da palavra subsistência um sentido que dificulta o reconhecimento de um modo de produzir e viver que não coloca em risco o próprio habitat.

Nas frestas da reprodução da cultura ancestral e suas práticas de reciprocidade a escola e o associativismo se instalam levando consigo uma razão própria, às vezes alheia e ameaçadora da permanência de práticas de reciprocidade camponesa. A menos que seu sentido seja disputado e ocupado pelos diferentes movimentos do campo, os vícios que carrega mediante a cumplicidade com o projeto de universalização da razão prática e instrumental, resulta no silenciamento de antigas práticas, deslocamentos hierárquicos, padrões de autoridade e fontes de poder. Esse processo pesa sobre a maioria dos contextos camponeses que tivemos contato ao longo de nossa trajetória de pesquisa na área, sob os imperativos hegemônicos de uma cultura política que emoldura o campo dentro de uma simples vocação de abastecimento.

\section{O lugar das reciprocidades nas políticas educacionais para o campo}

O Programa Nacional de Educação na Reforma Agrária (Pronera) consiste em uma política educacional para o campo cuja concepção (e modelo) é baseada na própria experiência da escolarização das populações do campo a partir dos movimentos sociais, nesse caso, o Movimento dos Trabalhadores Rurais Sem Terra (MST). Mediante parcerias das instituições públicas de ensino - universidades e institutos federais - e anuência dos movimentos sociais, o programa viabiliza cursos 
em caráter provisório a fim de dar conta da formação de profissionais em nível técnico, licenciatura e bacharelado. Com o objetivo original de formar os quadros profissionais para atuar nas áreas de reforma agrária (técnicos em enfermagem, educadores, profissionais de saúde coletiva), esse programa atualmente tem se dirigido para atenuar a defasagem de profissionais devidamente qualificados para educação no campo, ou seja, para equacionar a falta de professores que atuam fora de sua área de formação, os assim chamados "professores leigos".

As primeiras ações de escolarização foram cursos de alfabetização de jovens e adultos, mas a demanda e as experiências exitosas logo se expandiram para outros níveis de ensino. A experiência acumulada - com os cursos de licenciaturas, de pedagogia da terra, os cursos de nível técnico, as especializações, a residência agrária - criou uma demanda de institucionalização do programa como uma política pública de educação do campo em caráter permanente.

As chamadas Licenciaturas em Educação do Campo (Ledocs) representam uma segunda rodada de conquistas de setores camponeses organizados em torno da educação. Recebendo estudantes de origem exclusivamente rural, esses cursos copiam, da experiência do Pronera, o respeito ao calendário camponês - mediante a adoção da pedagogia da alternância como princípio - bem como o ensino contextualizado e inspirado na luta dos movimentos sociais. As Ledocs se diferem do Pronera na medida em que perdem o caráter provisório e passa a compor o quadro de cursos oferecidos regularmente pelas diversas universidades e institutos federais nos quais essas licenciaturas foram criadas, com corpo docente próprio e de composição interdisciplinar.

Com o objetivo específico de aumentar o número de educadores devidamente formados nas quatro áreas de conhecimento (ciências humanas, da natureza, linguagens e matemática) e também de criar quadros de agentes que protagonizem mudanças em suas comunidades de origem, as Ledocs consubstanciam o ideal de luta camponesa pensada a partir de um projeto educacional de cobertura nacional, articulado em fóruns, conferências e grupos temáticos de congressos acadêmicos. Colocadas diante uma das outras, as Ledocs apresentam vantagens que o Pronera não tem, e vice-versa. As Ledocs, por serem cursos regulares em nível superior, contam com amplo aparato institucional, corpo docente e técnico, apoio estudantil, programas de bolsas etc. No Pronera, apesar da matrícula que garante aos estudantes 
os mesmos direitos, os cursos comumente funcionam no ambiente próprio dos movimentos sociais, que os executam em regime de parceria com as universidades. Porém, é justamente por ocorrer sob o comando dos movimentos sociais que os cursos do Pronera são muitos zelosos no que se refere à questão da formação para militância, enquanto que, nas Ledocs, essa dimensão sofre embaraços frente ao perfil ainda bastante refratário que as universidades públicas têm em relação aos movimentos sociais.

Conforme se pode perceber, a constituição de uma política educacional do campo tem como antecedente as experiências acumuladas pelos movimentos sociais. Estes compuseram um longo repertório de práticas pedagógicas alinhadas com modelos educacionais que foram escolhendo e revestindo-os de princípios, conforme melhor se ajustavam aos seus ideais de luta. Basearam-se, segundo Medeiros (2014, p. 197) em

experiências concretas de processos educacionais realizados em espaços educativos nãoescolares, construídos historicamente, em acampamentos, assentamentos, marchas e outras ambiências organizativas, articulando-as a um projeto de sociedade produzido na trajetória de luta pela transformação social. Assim conformaram a proposta de uma política pública de Educação do Campo e pelo movimento dos próprios Movimentos [...]. Após mais de duas décadas de realização de ações de Educação do Campo, associa-se ao objetivo de ir mais longe, a necessidade de reafirmação de seus valores e agentes fundacionais, como forma de assegurar o avanço na direção pretendida, fazendo com que a ampliação seja, de fato, parte da conquista de outro Campo e outra Educação.

Com base nesses precedentes de luta dos movimentos sociais do campo e suas reflexões acumuladas e sistematizadas em fóruns, seminários e eventos temáticos, a educação do campo assume o caráter de um projeto social ou de um "Movimento da Educação do Campo" (MOLINA; ANTUNES-ROCHA, 2014); mas só se torna efetivamente uma política educacional no marco do Decreto $\mathrm{n}^{\circ} 7.342 / 2010$, que assim dispõe sobre a política de educação do campo:

A política de educação do campo destina-se à ampliação e qualificação da oferta de educação básica e superior às populações do campo, e será desenvolvida pela União em regime de colaboração com os Estados, o Distrito Federal e os Municípios, de acordo com as diretrizes e metas estabelecidas no Plano Nacional de Educação e o disposto neste Decreto. (BRASIL, 2010) 
Esta lei regulamenta a prestação de apoio técnico e financeiro por parte do governo federal (MEC) para todos os níveis (federal, estadual e municipal), na garantia de viabilizar as condições estruturais de implementação de ações tanto de educação básica no campo quanto de formação de professores, que por sua vez ficou originalmente a cargo do Pronera e posteriormente também das Ledocs. O Pronera, que tinha natureza de programa e, portanto, estava vulnerável aos interesses dos governos em exercício, com este novo ordenamento jurídico passa a ser instituído na administração pública estatal, perdendo seu caráter contingente e assumindo uma função de Estado, que por sua vez admite para si a necessidade de elevar os indicadores educacionais do campo. Sob certo ponto de vista, as Ledocs representam uma ocupação do espaço das universidades no sentido de que levam para dentro práticas pedagógicas que antes só existiam pelo esforço de alguns intelectuais dedicados a estudar o tema ou nos redutos dos grupos de pesquisa.

Apesar de ser um curso que na maioria das universidades só se conhece mediante muitas camadas de preconceitos, essas licenciaturas que carregam sua causa no nome e a presença de seus sujeitos dentro da universidade, acompanhados de seu ethos camponês, já é por si só responsável por uma profunda transformação dos próprios sujeitos no contato com esse ambiente de conhecimento institucionalizado e legítimo; e também da própria universidade, que é quase forçada a desmistificar a ideia - vulgar, porém presente - de campo como um passado já superado.

Colocados sob comparação com o passado, o Pronera e as Ledocs avançam no que se refere a constituição de uma autêntica política educacional ${ }^{3}$, de caráter amplo e sistemático, comportando ações que antes eram executadas em caráter "especial”, dentro das competências difusas da Secretaria de Educação Continuada, Alfabetização, Diversidade e Inclusão (Secadi). O modelo assim institucionalizado de formação de professores para o campo passou a se diferenciar entre os que, por indicação e protagonismo dos próprios movimentos, visando sobremaneira formar seus quadros militantes e profissionais, ingressam nas licenciaturas por meio de contratos, fomentado por repasses do governo federal e celebrado entre movimentos e Estado por meio do Pronera; ou entre os que ingrassam nas instituições de ensino superior

3 De acordo com o Dicionário de Educação do Campo: o campo de estudos da área de política educacional pode ser compreendido como aquele que analisa os interesses sociais e econômicos que se fazem presentes nos programas e ações governamentais no âmbito da educação. Cf.: CALDART, R. S.; PEREIRA, I. B.; ALENTEJANO, P.; FRIGOTTO G. (Orgs.). Dicionário da Educação do Campo. Rio de Janeiro, São Paulo: Escola Politécnica de Saúde Joaquim Venâncio, Expressão Popular, 2012. 
públicas mediante processo seletivo especial, geralmente chamado de vocacionado, no qual o uso de determinados filtros - como comprovação de residência no campo servem para identificar o caráter camponês dos candidatos, e depois disso estarão enquadrados na condição de estudante tal qual os demais, salvo suas especificidades.

Conquanto as ações do Pronera permanecem sob a condução dos movimentos sociais, são claramente preservados os aspectos de reciprocidade camponesa dentro das práticas pedagógicas que são próprias dos movimentos. Postas em comparação uma com a outra, o Pronera apresenta uma vantagem em relação as Ledocs, porque a ritualização dessas reciprocidades que no Pronera acontecem - nas circunstâncias acima descritas - de forma mais ou menos espontânea, nas Ledocs dependem muito da iniciativa dos próprios professores em executar projetos de extensão, grupos temáticos de pesquisa e/ou de discussões, eventos, seminários, encontros e uma série de outras ações educacionais que integralizem os componentes curriculares - que nas universidades recaem fortemente sobre o conhecimento científico - com as práticas de ordem mais subjetiva, como a mística, que revelam a estética da recíproca tipicamente camponesa.

\section{Considerações finais}

Uma vez subjugado pela cidade, o campo tornou-se um duplo histórico, uma espécie de pretérito-presente da ordem capitalista: de um lado, representa tudo que foi ou deveria ser superado em relação aos costumes, que por sua vez estavam associados a determinado estágio evolutivo das forças de produção, baseados na cooperação comunitária, ritualizado no cotidiano de trabalho e fora dele, envolto de significados místicos ou que escapam a racionalidade vulgar. De outro lado, representa um passado que se estende ou que resiste - depende de como se queira observar - e que por essa razão merece um lugar específico dentro das hierarquias das classificações sociais, sendo os sujeitos do campo tomados como dotados de robusta força física e reduzida capacidade de protagonizar um sentido próprio para suas vidas. São assim classificados pelo Estado em categorias diminutivas e reducionistas, tendo seu valor reconhecido apenas enquanto "produtores". Tomados meramente como uma contrapartida de abastecimento, não se deduz deles nada de exemplar em termos de cultura a não ser uma visão romantizada do camponês como ser dócil e generoso o que ratifica seu lugar social. 
Na sociedade urbana, o “dar, receber e devolver" foi integrado aos rituais da economia de mercado, a exemplo das trocas de presentes ao longo de diversas datas comemorativas ao longo do ano. Em contextos camponeses certamente estará presente o componente místico e de fé que uma pessoa tem em dividir seu excedente de produção, de tempo ocioso, de disponibilidade para ajudar, tudo isso como parte de um esforço comum de produzir a si mesmo e aos outros como seres recíprocos.

O que há de específico no campo é o campo das reciprocidades. A política educacional do campo representa um aliado estratégico para o movimento camponês na medida em que cria espaços onde essas reciprocidades são ensinadas, mediante técnicas, rituais e formas pedagógicas que corroboram para a legitimidade de uma forma de ser e estar no mundo ancestralmente herdado. Essa forma de ser e estar no mundo só pode se reproduzir no tempo pela apropriação de certas “oportunidades" de recriar a alteridade camponesa dentro de espaços como a escola do campo ou as associações de agricultores.

Estudos posteriores poderiam nos mostrar como os espaços institucionais de educação do campo cumprem um papel equivalente às antigas formas de cooperação para o trabalho. Nas farinhadas, típicas festas de colheita do semiárido nordestino, as pessoas produziam, além dos subprodutos da mandioca, a manutenção das relações de afeto e criação outras novas relações a partir das quais os grupos se perpetuam no tempo. A farinhada além de alimento produz também relações sociais. A mesma coisa se pode dizer da educação do campo, que produz conhecimento sobre si, aproxima pessoas de lugares diferentes, reforça os laços comunitários e cria também relações de afeto a partir das quais a cultura do campesinato se afirma como esteticamente bonita, ambientalmente justa e moralmente desejável.

\section{Referências}

ABRAMOVAY, Ricardo. Paradigmas do capitalismo agrário em questão. $3^{\circ}$ Ed. Edusp, São Paulo.

GOHN, Maria da Glória. Educação não formal, aprendizagens e saberes em processos participativos. Investigar em educação, v. 2, n. 1, 2014.

DURKHEIM, Émile. A educação moral. Editora Vozes Limitada, 2017.

ELIAS, Norbert. O Processo Civilizador: uma história dos costumes. Rio de Janeiro: Jorge Zahar, v. 1, 1994.

FREDA, Indursky. O ritual da mística no processo de identificação e resistência. RUA, 
v. 20, p. 109-125, 2014.

FOUCAULT, M. Microfísica do poder. Rio de Janeiro: Ed. Graal, 2004.

GALENO, Alex. Antonin Artaud: a revolta de um anjo terrível. Porto Alegre: Sulina, 2005.

GRISA, Catia; SCHNEIDER, Sergio. Três gerações de políticas públicas para a agricultura familiar e formas de interação entre sociedade e estado no Brasil. Revista de economia e sociologia rural, v. 52, p. 125-146, 2014.

LEFEBVRE, Henri. De lo rural a lo urbano. $4^{\mathrm{a}}$ ed. Barcelona: Ediciones península, 1978.

LEFEBVRE, Henri. O campo cego. In: - A revolução urbana. Belo Horizonte, Ed. UFMG, 1999.

MOLINA, Monica C.; ANTUNES-ROCHA, Isabel. Educação do Campo: história, práticas e desafios no âmbito das políticas de formação de educadores-reflexões sobre o PRONERA e o PROCAMPO. Reflexão e Ação, v. 22, n. 2, p. 220-253, 2014. Paulo, 2007. PIERUCCI, Antônio Flávio. Secularização em Max Weber: da contemporânea serventia de voltarmos a acessar aquele velho sentido. Revista brasileira de ciências sociais, $v$. 13, n. 37, p. 43-73, 1998.

POTRATZ, Raphael Henrique Ferreira. Do rural ao urbano: uma compilação de Lefebvre acerca da relação campo/cidade. RUA, v. 24, n. 2, 2018.

SABOURIN, Eric. Marcel Mauss: da dádiva à questão da reciprocidade. Revista Brasileira de Ciências Sociais, v. 23, n. 66, p. 131-138, 2008.

SABOURIN, Eric. Práticas de reciprocidade e economia de dádiva em comunidades rurais do Nordeste brasileiro. Raízes: Revista de Ciências Sociais e Econômicas, n. 20, p. 41-49, 1999.

VAN DER PLOEG, Jan Douwe. Sete teses sobre a agricultura camponesa. In: Agricultura familiar camponesa na construção do futuro. sn], 2009. p. 17-32.

Recebido: 01 Jul 2021

Aceito: 24 Ago 2021 